\title{
Value of Treating All Stages of Chronic Hepatitis C: A Comprehensive Review of Clinical and Economic Evidence
}

\author{
Roberto Nuño Solinís · Patricia Arratibel Ugarte · Ander Rojo • \\ Yuri Sanchez Gonzalez
}

Received: August 4, 2016 / Published online: October 25, 2016

(C) The Author(s) 2016. This article is published with open access at Springerlink.com

\section{ABSTRACT}

Introduction: The goal of chronic hepatitis C (CHC) treatment is to achieve a sustained virologic response (SVR). The new generation of direct-acting antivirals (DAAs) offers 90-100\% SVR rates. However, access to these treatments is generally limited to patients with advanced liver disease. The aim of this review is to provide an overview of the clinical and economic benefits of achieving SVR and to better understand the full value of $\mathrm{CHC}$ treatment in all stages of liver disease.

Methods: A comprehensive literature review was performed using the PubMed, Embase,

Enhanced content To view enhanced content for this article go to http://www.medengine.com/Redeem/ EAF6F06050476C59.

Electronic supplementary material The online version of this article (doi:10.1007/s40121-016-0134-x) contains supplementary material, which is available to authorized users.

R. Nuño Solinís · P. Arratibel Ugarte · A. Rojo Deusto Business School Health, University of Deusto, Bilbao, Basque Country, Spain

Y. Sanchez Gonzalez ( $\square)$

Health Economics and Outcomes Research, AbbVie Inc., North Chicago, IL, USA

e-mail: yuri.sanchezgonzalez@abbvie.com and Cochrane library databases to identify articles examining the clinical, economic, and quality of life benefits associated with SVR. Articles were limited to those published in English language from January 2006 through January 2016. Inclusion criteria were (1) patients with $\mathrm{CHC}$, (2) retrospective and prospective studies, (3) reporting of mortality, liver morbidity, extrahepatic manifestations (EHMs), and economic outcomes and, (4) availability of an abstract or full-text publication.

Results: Overall this review identified 354 studies involving more than 500,000 CHC patients worldwide. Evidence from 38 studies ( $n=73,861)$ shows a significant mortality benefit of achieving SVR in patients with all stages of fibrosis. Long-term studies with follow-up of 5-12 years suggest that, particularly among non-cirrhotic patients, there is a significant decrease in mortality in SVR versus non-SVR groups. Ninety-nine studies conducted in $235,891 \mathrm{CHC}$ patients in all stages of fibrosis show that SVR reduces liver-related mortality, incidence of hepatocellular carcinoma (HCC), and decompensation. A total of 233 studies show that chronic HCV 
infection is associated with several serious EHMs, some of which can have high mortality. Evidence from four modeling studies shows that delaying treatment to $\mathrm{CHC}$ patient populations could significantly increase mortality, morbidity, and medical costs.

Conclusions: There is a robust body of evidence demonstrating diverse sources of value from achieving SVR in all stages of liver disease. While access to treatment is generally limited to late-stage patients, less restrictive treatment strategies that target HCV eradication have the potential to abate the burdens of mortality, liver morbidity and extrahepatic manifestations, and the associated healthcare costs.

Keywords: Clinical/economic burden; Extrahepatic manifestations; Hepatitis C virus; Liver mortality/morbidity; Sustained virologic response

\section{INTRODUCTION}

Hepatitis C virus (HCV) infection represents a significant public health burden, with at least 150 million individuals chronically infected worldwide [1]. The goal of chronic hepatitis $\mathrm{C}$ (CHC) treatment is to achieve a sustained virologic response (SVR), which represents HCV clearance to undetectable levels and is considered a "virologic cure" [2]. Until 2011 the only available treatment was based on the combination of pegylated interferon and ribavirin (PEG/RBV). However, in genotypes 1 and 4 the rates of SVR were less than $50 \%$. In 2011 protease inhibitors in combination with PEG/RBV were approved for treatment of genotype 1 . While the SVR rates improved to $75-80 \%$, those treatments were associated with high toxicity and poor safety profile [3]. Novel, interferon (INF)-free direct-acting antiviral
(DAA) therapies have demonstrated SVR rates of $90-100 \%$ and high tolerability in clinical trials $[3,4]$. However, access to these agents is generally limited to patients with late-stage disease [5-7]. As such, it is important to offer a perspective on the consequences of this missed treatment opportunity in a broad range of patients.

This literature review was conducted with the objective of providing a comprehensive review of evidence demonstrating the value of achieving SVR at all stages of liver disease, focusing on four topics: (1) all-cause and liver-related mortality, (2) liver-related morbidity, (3) extrahepatic manifestations (EHMs), and (4) economic impact. The underlying hypothesis is that if HCV affects liver morbidity and EHMs, it should also impact liver-related and all-cause mortality and, ultimately, increase the economic burden of healthcare spending.

\section{METHODS}

The feasibility of conducting an original global systematic review was assessed using criteria from the preferred reporting items for systematic reviews and meta-analyses (PRISMA) [8] for the last 10 years. Preliminary searches revealed more than 400 references that potentially met our inclusion criteria (described below). Within these publications, search was further limited to review articles and meta-analyses published between 2006 and January 2016 as well as updates since the last publication date of a review or meta-analysis. However, for the section on EHMs there were no systematic reviews that addressed a comprehensive list of EHMs. Hence, we pooled the references from two recent review articles $[9,10]$ and conducted additional searches for 
any recent publications related to the EHMs associated with $\mathrm{CHC}$ treatment.

Searches were conducted using the Embase, PubMed, and Cochrane library databases, as well as a review of conference abstracts and general web searches. Inclusion criteria were (1) patients with CHC (excluding special populations such as liver transplant recipients, HIV-HCV co-infected patients, and recurrent or acute HCV cases), (2) retrospective and prospective studies (excluding case report studies), (3) reporting of mortality, liver morbidity, EHM, and economic outcomes, and (4) availability of an abstract or full text from the study publication.

\section{Compliance with Ethics Guidelines}

This article is based on previously conducted studies and does not involve any new studies of human or animal subjects performed by any of the authors.

\section{RESULTS}

Our search results are summarized in Fig. 1. For the first topic we identified a 2015 meta-analysis on the survival benefit of SVR. This paper evaluated 31 studies published between 1990 and November 2014 [11]. We then conducted an additional search to include all articles published between December 2014 and January 2016. This identified seven new studies on the impact of SVR on survival or mortality (Table S1).

For the topic on liver morbidity, our search identified one systematic review from 2011 of 67 studies [12] and one meta-analysis from 2010 of 26 studies [13]. During our search for publications from 2010 to January 2016, we identified six new studies (Table S2).
Our literature search did not find systematic reviews or meta-analyses that addressed all major types of extrahepatic manifestations identified in the literature. However, we identified and summarized one meta-analysis on the prevalence of a few select EHMs [14], and located multiple commentary-style reviews, which collectively summarized between 150 and 250 studies. We also leveraged two recent reviews $[9,10]$ and pooled their references into one database, with a total of 350 references. This database was manually screened and prioritized for high-quality evidence based on study type (prospective versus retrospective) and size (Table S4). We identified seven epidemiological studies on several types of EHMs and 12 publications that studied the impact of SVR on EHMs (Table S5).

Lastly, on the topic of economic value, our search identified four studies on different strategies for treating $\mathrm{HCV}$. We came across one systematic review on the methodology of cost-effectiveness analysis of antiviral therapy. We leveraged and updated that review to provide a summary of cost-effectiveness publications (Table S6). Overall, this review summarizes results from 354 studies conducted with more than 500,000 CHC patients worldwide. The studies in each section are summarized in a decreasing order of strength of evidence, meta-analysis followed by prospective and retrospective studies.

\section{Survival Benefit of SVR}

Our review shows that 38 studies with a total of 73,861 HCV patients have demonstrated significant improvement in long-term survival among patients who achieve an SVR versus those who do not. While this benefit is significant in all HCV patients, cirrhotic or non-cirrhotic, patients who achieve SVR at 


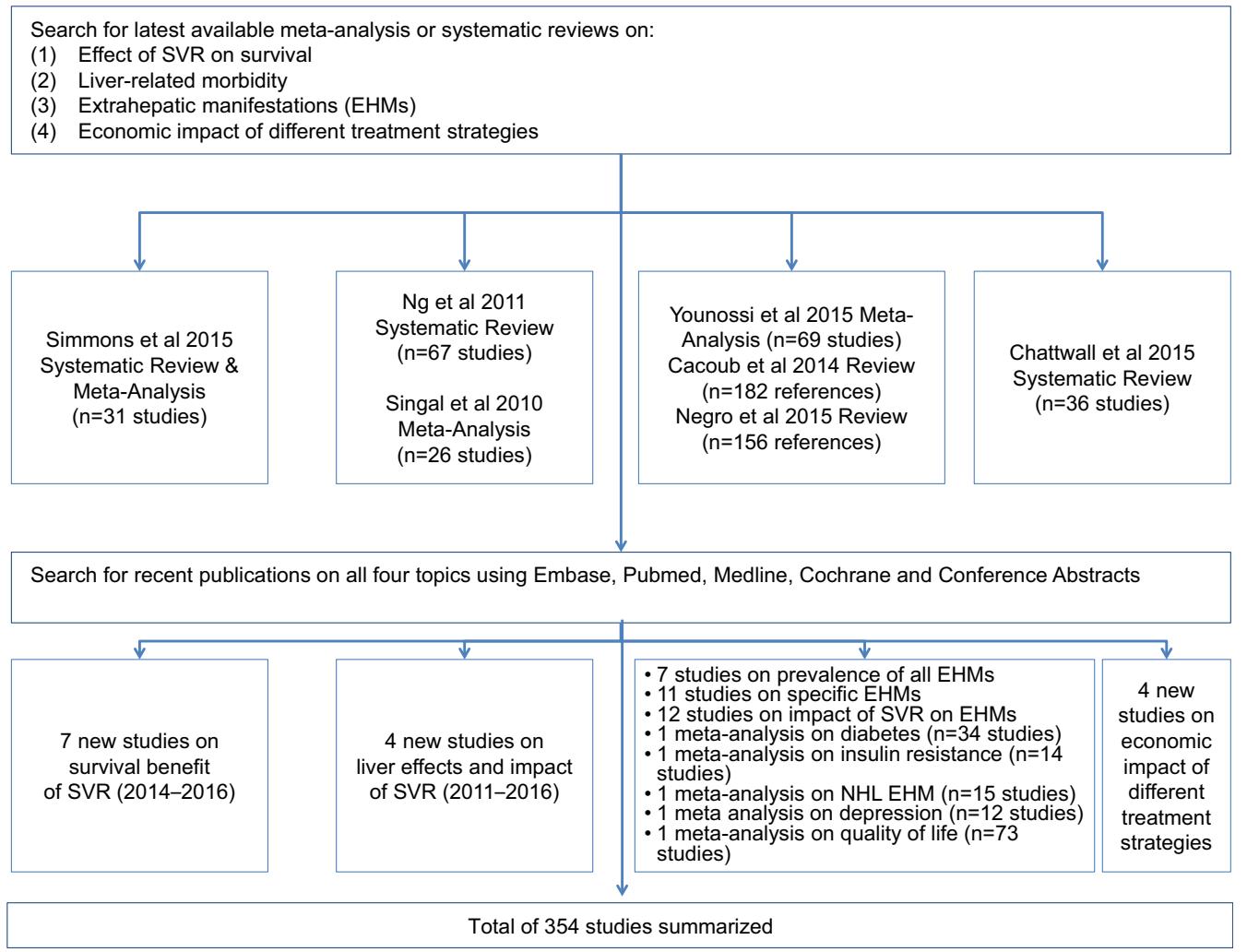

Fig. 1 Summary of search results

earlier disease stages have the lowest mortality risk.

A meta-analysis of 31 studies $(n=33,360$ and median follow-up of 5.4 years) conducted between 2001 and 2014 found that there is a significant survival benefit of achieving an SVR compared with unsuccessful treatment in a broad range of populations infected with HCV. The general population group (monoinfected patients at all disease stages) included 17 studies $(n=28,451)$, with approximately $33 \%$ of the patients with F1 stage of liver fibrosis. The cirrhotic patient group included nine studies ( $n=2886$ ) with $100 \%$ of the patients in F3 stage or higher. In this meta-analysis, the adjusted hazard ratio (aHR) of all-cause mortality for HCV patients achieving SVR vs non-SVR was $0.50 \quad(95 \%$ CI $0.37-0.67)$ in the general population and 0.26 (95\% CI $0.18-0.74)$ in the cirrhotic group. The pooled 5-year mortality rates were significantly lower for patients achieving SVR compared with non-SVR in all three populations. The authors concluded that after adjusting for potential confounding factors, an SVR was associated with approximately a $50 \%$ and $74 \%$ decreased risk of all-cause mortality compared with not achieving an SVR in the general and cirrhotic populations, respectively [11].

A 12-year follow-up study was conducted with 24,968 HCV patients from the Kaiser Permanente integrated healthcare system in the USA. In this study, mortality was markedly higher in patients with cirrhosis who did not achieve SVR (23.7\%) vs cirrhotics who did achieve SVR (8.1\%), nearly a threefold increase $(p<0.0001)$. Among non-cirrhotics, there was a 2.5 -fold increase in mortality in those who did 
not achieve SVR (5.3\%) compared to those who achieved SVR (2.1\%). Importantly, patients who achieved SVR with cirrhosis had nearly four times higher mortality risk than patients who achieved SVR without cirrhosis [15].

Another large observational study with 9143 patients (moderate to advanced fibrosis) with a median follow-up of 6.4 years in four US health systems found that successful treatment leading to SVR significantly reduced mortality (aHR $0.40,95 \%$ CI $0.28-0.56$ ) compared to no treatment [16].

In France access to antiviral therapy is generally limited only to moderate-to-advanced fibrosis stage patients. To highlight the high incidence of mortality and morbidity in early Metavir fibrosis stage patients (F0 and F1) Jeźequel et al. conducted a follow-up study with 820 patients. After a median follow-up of 4.6 years, an increased fibrosis stage to F3 or F4 was observed in $15.3 \%$ of F0-F1 patients and $48 \%$ of F2 patients. In addition, $46.7 \%$ of F3 patients progressed to F4. After a median follow-up of 11.9 years, 248 patients died $(16.7 \%)$, more frequently in fibrosis stages F2-F4 (24.4\%) than in F0-F1 $(11.5 \%)(p<0.05)$. Median survival at 5, 10 , and 15 years after the first liver biopsy was 97.4, 93.1, and 87\% in F0-F1 patients and 93.2, 83.4, and $65.4 \%$ in F2-F4 patients. Survival was higher in treated patients with SVR than in untreated patients or treatment failures regardless of fibrosis stage $(p<0.01)[17,18]$.

Propensity score analysis of 2743 Japanese patients followed for more than 10 years (range 10.5-14.2 years) showed that the eradication of $\mathrm{HCV}$ (defined as achieving SVR) significantly reduced all-cause mortality (HR 0.265; 95\% CI 0.06-0.38), including non-liver-related mortality (HR 0.439; 95\% CI $0.23-0.83$ ), compared to no treatment [19]. Another Japanese study of 1125 elderly HCV patients used propensity-score-adjusted Cox proportional analysis to show that achieving an SVR significantly reduced total mortality risk (HR 0.077, CI 0.011-0.550; $p=0.011$ ), compared to no SVR or no treatment [20].

A retrospective analysis of 427 French HCV patients with advanced liver disease found that the risk of death or liver transplantation was significantly lower in SVR than in non-SVR patients and in non-SVR than in untreated patients (hazard ratios, 0.35 and 0.51, respectively; $p<0.05$ ), suggesting that even unsuccessful treatment may convey survival benefits [21]. In a long-term retrospective study of 714 Austrian HCV patients with advanced liver disease, the 5- and 10-year mortality rates were $1.8 \%$ and $2.7 \%$ in the SVR group and $8.6 \%$ and $19.1 \%$ among non-SVR patients, respectively $(p<0.001)$ [22].

\section{Liver-Related Morbidity}

According to the National Institute of Health Consensus, the most important sequelae of chronic HCV infection are progressive liver fibrosis leading to cirrhosis (compensated-CC or decompensated-DCC), end-stage liver disease, and hepatocellular carcinoma (HCC) [23]. In our review we found one systematic review of 67 studies, one meta-analysis of 26 studies, and six recent studies showing strong evidence for high burden of liver-related complications in $\mathrm{CHC}$ patients in all stages of fibrosis. These publications cumulatively provide long-term follow-up evidence from 235,891 CHC patients.

A systematic review of 67 studies ( $n=17,025)$ published during 1991 and 2011 worldwide found that SVR reduced liver-related mortality among patients with CHC (3.3- to 25-fold), the incidence of HCC (1.7- to 4.2-fold), and hepatic decompensation (2.7- to 17.4-fold). The authors concluded that the benefits were 
seen in patients with all stages of liver fibrosis, and the effects were significant even in advanced fibrosis stages [12].

A meta-analysis of 26 studies $(n=15,621)$ published during 1990 and 2008 found high rates of liver-related mortality $(2.73 \%$ per year; 95\% CI 1.38-4.080), HCC (3.22\% per year, 95\% CI 2.02-4.42), and hepatic decompensation (2.92\% per year; 95\% CI 1.61-4.22) among patients with advanced fibrosis who failed treatment. Patients with SVR are significantly less likely than patients who experienced treatment failure to develop liver-related mortality (relative risk [RR] 0.23; 95\% CI 0.10-0.52), HCC (RR 0.21; 95\% CI 0.16-0.27), or hepatic decompensation (RR 0.16; 95\% CI 0.04-0.59). Among studies of patients with varying levels of fibrosis, the annual rates of decompensated cirrhosis, HCC, and/or liver-related mortality vary from 0.56 to $1.39 \%$. This meta-analysis included 20 studies with patients all stages of fibrosis and five studies with patients in F3 or F4 fibrosis [13].

In a French prospective cohort study of 1323 HCV patients with compensated cirrhosis treated with DAAs, there was a three- to five-fold reduction in critical events, liver-related or not, among patients achieving SVR, which led to improved overall and liver-related survival. Furthermore, SVR was an independent factor associated with a decreased incidence of HCC (5 years cumulative incidence: $3.3 \%$ vs. $21.8 \%$, HR 0.21 [0.13-0.36], $\quad p<0.001)$ and hepatic decompensation (5 years cumulative incidence: $4.2 \%$ vs. $24.0 \%$, HR 0.17 [0.10-0.27], $p<0.001$ ) [24].

In a long-term prospective study of up to 23 years with 194 cirrhotic Italian HCV patients, the rate of HCC was higher in patients without SVR compared to those with SVR: 2.7/100 person-years (95\% CI 2.1-3.5) and
1.4/100 person-years $\quad(95 \% \quad$ CI $\quad 0.7-2.7)$, respectively $[p=0.02, \quad$ HR $\quad(95 \%$ CI $) \quad 0.42$ (0.20-0.89)]. Using multivariate analysis the authors also found that SVR was not associated with risk reduction of HCC development if cirrhosis has already occurred. On the basis of these results, the authors of this study suggested that effective antiviral treatment should be recommended at early disease stages [25].

In a long-term prospective study with 351 HCV patients in Sweden (most patients were treated with PEG/RBV), the incidences of HCC, any liver complication, liver-related death, and overall death per 100 person-years were significantly lower in the time lived with SVR $(1.0,0.9,0.7$, and 1.9), compared to the time lived treated but without SVR $(2.3,3.2,3.0$, and 4.1 ) and the time lived without treatment (4.0, $4.9,4.5$, and 5.1) [26]. This supports the notion that $\mathrm{CHC}$ treatment mitigates the risk of liver morbidity, even when it is unsuccessful.

Tada et al.'s Japanese study $(n=2743)$ showed that the eradication of HCV (defined as achieving SVR) reduced the incidence of HCC (HR 0.275; 95\% CI 0.156-0.448) [19]. Another Japanese study by Kobayashi et al. $(n=1125)$ showed that achieving an SVR significantly reduced HCC risk (HR 0.118, CI 0.029-0.476; $p=0.003)$, compared to no SVR or no treatment [20].

A large retrospective database study of US Veteran Affairs patients $(n=187,860)$ showed that initiating treatment before Fibrosis-4 score (FIB4) >1.00 reduced morbidity by $41 \%$ and death by $36 \%$ [27]. Similar results were observed in an insurance database study in Turkey showing that mortality $(2.27 \%$ vs. $5.31 \% ; p<0.001)$ and HCC rates $(0.69 \%$ vs. $1.96 \% ; p<0.001)$ were lower for treated patients compared to untreated patients [28]. 


\section{Extrahepatic Manifestations (EHMs)}

In addition to liver-related morbidity, chronic $\mathrm{HCV}$ infection is associated with changes in organ systems outside the liver, including metabolic, cardiovascular, and neurological systems, and with autoimmune and immune-mediated conditions such as mixed cryoglobulinemia (MC), thyroid disease, and glomerulonephritis. According to a recent review up to $74 \%$ of $\mathrm{CHC}$ patients suffer from EHMs [10]. There is a significant amount of evidence on prevalence and burden of EHMs in CHC. Recent reviews have included summaries from 150 to 250 studies. In this review we provide an overall summary from 233 studies on the epidemiology and value of SVR for reducing the risk of EHMs.

\section{Studies Estimating Broad Prevalence of EHMs}

A recent meta-analysis of 69 studies estimated the overall burden of seven EHMs due to HCV (Table S3). In this analysis the pooled prevalence estimate of MC ( $n=14$ studies) was $32 \%$ in the HCV group (95\% CI 21-43\%) and 3\% (95\% CI $0-8 \%$ ) in the non-HCV group ( $n=3$ studies). The pooled prevalence of diabetes mellitus (DM) ( $n=16$ studies) among HCV patients was $15 \%$ (95\% CI 13-18\%) compared to $10 \%$ (95\% CI $4-15 \%)$ in the non-HCV population. The pooled odds ratio (OR) of developing chronic kidney disease/end-stage renal disease (CKD/ESRD) in patients with $\mathrm{HCV}$ compared to the non-HCV group ( $n=11$ studies) was $1.29 \quad(95 \% \quad$ CI $1.13-1.45)$. The risk of lymphoma was $64 \%$ higher (OR 1.64; 95\% CI 1.18-2.11) in patients with HCV compared to the non-HCV population. The pooled prevalence estimate of lichen planus among $\mathrm{HCV}$ ( $n=11$ studies) was
2.1\% (95\% CI 1.1-3.1\%) while the prevalence in non-HCV ( $n=3$ studies) was $1.4 \%$ (95\% CI $0-3.4 \%)$. The pooled prevalence of Sjögren's syndrome ( $n=6$ studies) was $1.11 \%(95 \% \mathrm{CI}$ $0.17-0.53 \%)$ compared to $0.11 \% \quad(95 \%$ CI $0.09-0.13 \%)$ in the non-HCV group $(n=1$ study). The pooled prevalence of porphyria cutanea tarda (PCT) among $\mathrm{HCV}$ patients $(n=5)$ was $0.7 \%(95 \%$ CI $0.2-1.1 \%)$ whereas the prevalence in the non-HCV group $(n=1$ study) was $0.06 \%$ (95\% CI 0.05-0.07) [14].

Globally, a relatively significant prevalence of EHMs has been found in CHC patients in five retrospective studies conducted in Italy $(n=440)$, Poland $(n=340)$, China $(n=297)$, Romania $(n=162)$, and Turkey $(n=62)$ [29-33].

\section{Studies on Specific EHMs}

\section{Mixed Cryoglobulinemia (MC)}

Cacoub et al. suggests that the overall 5-year survival rate after the diagnosis of vasculitis ranges from 90 to $50 \%$, in case of renal involvement [10]. In our review we found five studies with a total of $810 \mathrm{CHC}$ patients which also show that HCV-related MC can lead to high mortality in some patients [34-38]. A study from Spain $(n=279)$ found that HCV-related cryoglobulinemia may result in progressive (renal involvement) or acute (pulmonary hemorrhage, gastrointestinal ischemia, central nervous system involvement) life-threatening organ damage. During mean follow-up of 14 months the mortality rate from these manifestations in the study group was between $20 \%$ and $80 \%$ [37]. In a long-term efficacy study in France $(n=72)$, it was shown that an early virologic response (odds ratio 3.53, 95\% confidence interval [CI] 1.18-10.59) was independently associated with a complete clinical response of MC [38]. 


\section{Non-Hodgkin's Lymphoma (NHL)}

A large meta-analysis of 15 case-control studies and three prospective studies with a total number of 12,235 $\mathrm{CHC}$ patients estimated the pooled RR of NHL among HCV-positive individuals as 2.5 (95\% CI 2.1-3.0) [39]. Another meta-analysis conducted primarily with Italian and Japanese studies including 4049 NHL patients and 1813,480 controls also found a strong positive association between anti-HCV seropositive test subjects and risk of NHL (OR for NHL was 5.70, 95\% CI 4.09-7.96, $p<0.001$ ) [40].

\section{Type II Diabetes Mellitus (DM)}

In a meta-analysis of 34 studies the pooled estimate indicated significant DM risk in HCV-infected cases in comparison to non-infected controls in both retrospective $\left(\mathrm{OR}_{\text {adjusted }}=1.68, \quad 95 \% \quad \mathrm{CI} \quad 1.15-2.20\right)$ and prospective studies $\left(\mathrm{HR}_{\text {adjusted }}=1.67,95 \% \mathrm{CI}\right.$ 1.28-2.06) [41].

\section{Insulin Resistance (IR)}

In a retrospective study of the US National Health and Nutrition Examination Survey (NHANES) $(n=173)$ CHC was independently associated with the presence of IR [OR (95\% CI) 2.06 (1.19-3.57)], DM [OR 2.31 (1.18-4.54)], and hypertension [OR 2.06 (1.30-3.24)] [42]. Recently, the evidence of IR in HCV patients was confirmed by a meta-analysis of 14 studies, involving 3659 patients. This analysis showed that the RR of IR among HCV subjects with advanced hepatic fibrosis (F3 and F4) was 1.63 [95\% confidence interval (CI) 1.34-2.01], compared to patients with F0-F2 fibrosis [43].

In a recent review, Negro et al. suggested that the most compelling evidence that HCV causes IR is the observation that curing HCV with antiviral therapy results in reduced levels of IR, citing a Japanese study of 89 patients, which showed that clearance of HCV improves IR, beta-cell function, and hepatic IRS1/2 expression $[9,44]$.

\section{Renal Insufficiency}

In a retrospective study of patients in the US Veteran Affairs healthcare system $(n=1928 \mathrm{HCV}$ antibody positive and $n=23,854 \mathrm{HCV}$ antibody negative), after adjustment for age, race, gender, diabetes, and hypertension, HCV-positive veterans had a 40\% higher odds for renal insufficiency (odds ratio 1.40; 95\% CI 1.11-1.76) as compared with HCV-negative veterans [45].

A large-scale community study $(n=54,966)$ on the effect of viral hepatitis (HCV or HBV) on nephropathy in Taiwan found that $\mathrm{HCV}$ infection alone (OR 1.26; 95\% CI 1.17-1.38) was an independent risk factor for CKD, but not $\mathrm{HBV}$ infection alone or $\mathrm{HBV} / \mathrm{HCV}$ coinfection [46].

\section{Cardiovascular Disorders}

A meta-analysis of six studies showed a strong link between HCV and risk of stroke, with 22,171 HCV-infected individuals and 87,418 controls, and an estimated pooled OR of 1.58 $(0.86,2.30)$ [47]. Similarly, high risk of stroke was observed in a large retrospective database study in Taiwan ( $n=4084 \mathrm{HCV}$ and $n=16,376$ controls), with a cumulative risk of stroke for people with and without HCV of $2.5 \%$ and $1.9 \%$, respectively $(p<0.0001)$. Compared to people without $\mathrm{HCV}$, the adjusted HR of stroke was 1.27 (95\% CI 1.14-1.41) for people with HCV [48].

A strong link between $\mathrm{HCV}$ and coronary artery disease (CAD) was observed in a large database study of US Veteran Affairs patients ( $n=82,083 \quad$ HCV-infected and $n=89,582$ HCV-uninfected). The study showed that HCV infection was associated with a higher risk of CAD (HR 1.25; 95\% CI 1.20-1.30) [49]. 


\section{Depression}

A meta-analysis including 12 studies ( $n=130,039$ in 5 cross-sectional, 3 longitudinal, 3 prospective, and 1 retrospective chart review) estimated the pooled prevalence of depression among $\mathrm{HCV}$ patients at $24.5 \%$ (95\% CI 14.1-34.9\%) [50]. This rate of depression is almost $20 \%$ higher than the rate of depression in the general population.

\section{Quality of Life}

A systematic review of 73 studies $(n=130,039)$ concluded that HCV has a negative impact on health-related quality of life (HRQL, 61 studies), fatigue (20 studies), and work productivity (3 studies) [51].

\section{Studies on Value of Antiviral Therapy in Patients with HCV-Related EHMs}

In our review we found 15 studies ( $n=12,974)$, which have demonstrated value of antiviral therapy in lowering the burden of EHMs in CHC patients (Table S4). A prospective study of 424 CHC patients in Italy showed that in the majority of patients (36 patients, 57\%) all mixed cryoglobulinemia syndrome (MCS) symptoms persistently disappeared after achieving SVR [52]. In a retrospective study of Japanese patients $(n=3209)$ the HR of lymphomagenesis in 1048 patients with SVR was significantly lower than in patients with persistent infection (hazard ratio $0.13 ; p<0.05$ ), demonstrating that SVR protects against the development of malignant lymphoma in patients with chronic HCV [53]. Another Japanese study of 2842 patients showed that SVR caused a two-thirds reduction in the risk of type $2 \mathrm{DM}$ development in HCV-positive patients treated with antiviral therapy [54]. In a US randomized study of 1121 CHC patients, SVR was associated with improvement at follow-up on all Short-Form Health Survey (SF-36) and Functional Systems Scores (FSS) components [55]. SF-36 is a validated and commonly used questionnaire for assessing HRQOL; it has 36 measures with 8 subscales including physical functioning and vitality.

\section{Economic Value of Treatment}

The cost-effectiveness of antiviral therapy (including DAAs) has been demonstrated in 35 published studies, which include 30 Markov models, 2 micro simulations, 1 discrete event simulation, and 1 hybrid model (Table S6). Fifteen of the 35 analyses were conducted in the USA, 5 in Italy, 4 in the UK, and 3 in Spain. Cost-effectiveness of treatment for naïve and non-cirrhotic patients was specifically analyzed in 11 and 4 analyses, respectively. We conducted additional search for any cost-effectiveness analyses, economic impact, or database studies examining the impact of delaying or deferring antiviral treatment. Overall, these modeling analyses show that newer-generation treatments (e.g., INF-free DAAs) are more cost-effective than older (e.g., INF-based) regimens, and early treatment is cost-effective compared to treatment at late CHC stages.

A US decision analytic model analyzed the cost-effectiveness of six novel DAAs at different stages of fibrosis. Their analysis shows that treatment with DAA as early as stage F1 is cost-effective (incremental cost-effectiveness ratios [ICERs] of US\$50,000-150,000 per quality-adjusted life year [QALY] gained) and less than US\$50,000 per QALY gained when treatment is initiated at stage F2 vs stage F3 [56].

A Markov modeling analysis in the USA showed that treatment with a DAA at F2 rather than F3-F4 is projected to have even greater efficacy, decreasing the average number 
of cases of DCC by $63.3 \%$, HCC by $89.0 \%$, liver transplants by $83.3 \%$, and HCV-related deaths by $84.5 \%$ [57]. Similar results were observed for a model in the Spanish setting, which demonstrated that, compared to delayed administration of therapy at F4, initiating DAA treatment at early disease stages (F2-F3) reduced the incidence of new cases of liver-disease complications and was associated with cost savings for the Spanish National Health System in previously untreated genotype 1 HCV patients [58].

A natural history Markov model showed that initiation of treatment with DAAs at later stages of fibrosis resulted in greater average annual lifetime post-treatment costs and fewer life years compared to treatment initiation at earlier fibrosis stages; in particular, treatment-naïve patients treated in Fo stage had average annual medical costs of US\$314 (US\$228 discounted), whereas patients treated in F4 stage had over 10-fold greater annual medical costs (US\$3187) [59].

A disease progression model estimated the cost-effectiveness of using PEG/RBV and/or PEG/ RBV with protease inhibitors in 16 countries and showed that treatments with higher efficacy and increased uptake are needed to control $\mathrm{HCV}$ burden [60]. Bruggmann et al. developed a follow-up model to assess the impact of delaying treatment scenarios in Switzerland. The model showed that a 2-year delay in treatment could reduce the impact of disease burden control efforts by $10 \%$, while a 5 -year delay could reduce the impact by $30 \%$ [61]. The authors concluded that a substantial reduction in disease burden could be achieved by means of both higher efficacy drugs and increased treatment uptake, underscoring the importance of comprehensive treatment with INF-free DAA therapies [62].

\section{DISCUSSION}

In our review of the literature we found a large body of evidence demonstrating diverse sources of value for CHC patients achieving SVR in all stages of liver disease. Overall, this review summarizes results from 354 studies conducted in more than 500,000 patients. The summarized evidence confirms our hypothesis that HCV affects liver morbidity and EHMs, which leads to increased liver-related and all-cause mortality and high economic burden. The evidence also strongly demonstrates that achievement of SVR can increase survival, reduce liver and extrahepatic morbidity, and lower long-term costs. Even unsuccessful CHC treatment appears to have a protective effect against mortality and liver morbidity. Furthermore, treatment with newer-generation regimens (e.g., INF-free DAAs) is generally cost-effective compared to older (e.g., INF-based) regimens. Similarly, treatment in early fibrosis stages is cost-effective relative to late treatment.

Most notable is the evidence from 38 studies showing $(n=73,861) \quad$ significant mortality benefit of SVR in patients with all stages of fibrosis. Ninety-nine studies conducted in 235,891 CHC patients in all stages of fibrosis have shown that SVR reduces liver-related mortality (3.3- to 25-fold), incidence of HCC (1.7- to 4.2-fold), and hepatic decompensation (2.7- to 17.4-fold) [12, 13]. Evidence from modeling studies confirms these results by showing that delaying treatment could significantly increase mortality, morbidity, and medical costs. Additionally, there are more than 200 studies which have shown that chronic $\mathrm{HCV}$ infection is associated with several serious EHMs, some of which can have high mortality $[9,10]$. 
Despite a compelling and robust body of clinical and economic evidence, current access to DAAs has been limited largely to patients with advanced liver disease. This restriction on access is either due to a perception that patients in early stages of fibrosis can wait and/or due to the short-term costs of treating patients in all fibrosis stages. However, as this review shows, there is compelling clinical and economic evidence that treatment for patients in early and all stages of fibrosis improves survival, reduces liver-related and extrahepatic morbidity, and is cost-effective.

In spite of numerous challenges, some countries or regions have implemented comprehensive treatment strategies for CHC. In 2013, when INF-free DAAs were licensed, Georgia engaged partners to develop a national $\mathrm{HCV}$ prevention and control plan targeting the elimination of $\mathrm{HCV}$ transmission and disease [63]. Similarly, the Hepatitis Prevention, Control, and Elimination (HPCE) Program was officially launched in September 2014 to radically change the current state of viral hepatitis in Mongolia and significantly reduce the disproportionate and sustained burden of liver cirrhosis, liver cancer, and mortality [64]. In Egypt, the government has launched a comprehensive HCV treatment program with a goal to treat 300,000 people a year (WHO 2015). In these exemplary cases, a strong healthcare infrastructure and political will are crucial to battle HCV by implementing effective screening and treatment programs [65]. In Australia, the federal government has announced that it will subsidize new breakthrough HCV treatments to cure all patients [66]. The implementation and outcomes of these programs should be closely monitored as they could provide valuable real-world policy lessons for other regions. Recently, the French government announced plans to provide universal access to new HCV medications [67].

The demonstrated value of achieving SVR underscores the importance of comprehensive treatment strategies targeting all stages of liver disease and based on the most effective and tolerable class of DAA regimens. It should be further noted that the majority of the studies summarized here were conducted with INF-based antivirals which had relatively low cure rates and high toxicity. The new generation of DAAs offer $90-100 \%$ cure rates and have a significantly better safety profile, making the case even stronger to offer these treatment options to patients in all stages of liver disease [3].

There are some limitations of our review. As a result of the broad scope of the topic and robust body of evidence it was not possible to conduct a full systematic review. However, to provide a summary on relevant topics we leveraged the highest-quality evidence such as meta-analyses and systematic reviews. Additionally, our review focused only on the treatment for HCV. There are other areas such as disease awareness, diagnosis, and monitoring which also need policy interventions for developing successful and comprehensive HCV eradication plans.

Though this review demonstrates the need and value of treatment for all HCV patients, expansion of access should be considered within comprehensive plans aimed at the prevention, control, and eradication of $\mathrm{HCV}$, taking into account the budgetary impact and health system infrastructure of each country. The design and implementation of healthcare solutions for effective $\mathrm{CHC}$ control remains a crucial topic of analysis in order to capture the full value of effective and comprehensive treatment opportunities. 


\section{ACKNOWLEDGMENTS}

Sponsorship and article processing charges for this study were funded by AbbVie, which participated in the interpretation of data, review, and approval of the study. All named authors meet the International Committee of Medical Journal Editors (ICMJE) criteria for authorship for this manuscript, take responsibility for the integrity of the work as a whole, and have given final approval for the version to be published. All authors had full access to all of the data in this study and take complete responsibility for the integrity of the data and accuracy of the data analysis. The authors would like to thank Saurabh Aggarwal for valuable research support. Saurabh Aggarwal is Principal and Co-Founder of NOVEL Health Strategies, which received payment from AbbVie for conducting research analysis.

Disclosures. Yuri Sanchez Gonzalez is an employee of AbbVie Inc. and owns AbbVie stock or stock options. Roberto Nuño Solinís, Patricia Arratibel Ugarte, and Ander Rojo are employees of the University of Deusto but have nothing to disclose.

Compliance with Ethics Guidelines. This article is based on previously conducted studies and does not involve any new studies of human or animal subjects performed by any of the authors.

Open Access. This article is distributed under the terms of the Creative Commons Attribution-NonCommercial 4.0 International License (http://creativecommons.org/licenses/ by-nc/4.0/), which permits any noncommercial use, distribution, and reproduction in any medium, provided you give appropriate credit to the original author(s) and the source, provide a link to the Creative Commons license, and indicate if changes were made.

\section{REFERENCES}

1. Shire NJ, Sherman KE. Epidemiology of hepatitis C virus: a battle on new frontiers. Gastroenterol Clin N Am. 2015;44(4):699-716 (Epub 2015/11/26. eng).

2. AASLD-IDSA. Recommendations for testing, managing, and treating hepatitis C. http://www. hcvguidelines.org/full-report-view. Accessed 19 Dec 2015.

3. González-Grande R, Jiménez-Pérez M, González Arjona C, Mostazo Torres J. New approaches in the treatment of hepatitis C. World J Gastroenterol. 2016.

4. Attar BM, Van Thiel DH. Hepatitis C virus: a time for decisions. Who should be treated and when? World J Gastrointest Pharmacol Ther. 2016;7(1):33-40.

5. Barua S, Greenwald R, Grebely J, Dore GJ, Swan T, Taylor LE. Restrictions for Medicaid reimbursement of sofosbuvir for the treatment of hepatitis $C$ virus infection in the United States. Ann Intern Med. 2015;163(3):215-23.

6. Swan T. Overview of new treatments for hepatitis C virus: moving towards a public health agenda. http:// www.who.int/selection_medicines/committees/ expert/20/reviews/overview-new-treatments-HEP-C_ 13-Apr-15.pdf. Accessed 19 Dec 2015.

7. Lima VD, Rozada I, Grebely J, Hull M, Lourenco L, Nosyk B, et al. Are interferon-free direct-acting antivirals for the treatment of $\mathrm{HCV}$ enough to control the epidemic among people who inject drugs? PLoS One. 2015;10(12):e0143836.

8. Moher D, Shamseer L, Clarke M, Ghersi D, Liberati A, Petticrew M, et al. Preferred reporting items for systematic review and meta-analysis protocols (PRISMA-P) 2015 statement. Syst Rev. 2015;4(1):1-9.

9. Negro F, Forton D, Craxì A, Sulkowski MS, Feld JJ, Manns MP. Extrahepatic morbidity and mortality of chronic hepatitis C. Gastroenterology. 2015;149(6):1345-60.

10. Cacoub P, Gragnani L, Comarmond C, Zignego AL. Extrahepatic manifestations of chronic hepatitis $C$ virus infection. Dig Liver Dis. 2014;46(S5):S165-73. 
11. Simmons B, Saleem J, Heath K, Cooke GS, Hill A. Long-term treatment outcomes of patients infected with hepatitis $C$ virus: a systematic review and meta-analysis of the survival benefit of achieving a sustained virological response. Clin Infect Dis. 2015;61(5):730-40.

12. $\mathrm{Ng} \mathrm{V}$, Saab S. Effects of a sustained virologic response on outcomes of patients with chronic hepatitis C. Clin Gastroenterol Hepatol. 2011;9(11):923-30.

13. Singal AG, Volk ML, Jensen D, Di Bisceglie AM, Schoenfeld PS. A sustained viral response is associated with reduced liver-related morbidity and mortality in patients with hepatitis $C$ virus. Clin Gastroenterol Hepatol. 2010;8(3):280-8.e1.

14. Younossi ZM, Park H, Adeyemi A, Stepanova M, Henry L. A meta-analytic estimation of the burden of extra hepatic manifestations of hepatitis C. Gastroenterology. 2015;148(4):S503.

15. Nyberg LM, Li X, Yang SJ, Chiang K, Cheetham TC, Caparosa $\mathrm{S}$, et al. The association of sustained virological response and all-cause mortality after interferon-based therapy for chronic hepatitis C (HCV) in a large U.S. community-based health care delivery system. Hepatology. 2015;62:252A.

16. Lu M, Li J, Rupp LB, Holmberg SD, Moorman AC, Spradling PR, et al. Effect of hepatitis C antiviral therapy on all-cause mortality and development of cancer in the chronic hepatitis cohort study (CHeCS). J Hepatol. 2015;62:S618-9.

17. Jeźequel C, Bardou-Jacquet E, Desille Y, Renard I, Lainé F, Lelan C, et al. Survival of patients infected by chronic hepatitis C and FOF1 fibrosis at baseline after a 15 years follow-up. J Hepatol. 2015;62:S589.

18. AASLD-IDSA. HCV guidance: recommendations for testing, managing, and treating hepatitis C. http:// hcvguidelines.org/sites/default/files/HCV-Guidance October_2016_a.pdf. Accessed 1 Mar 2016.

19. Tada T, Kumada T, Toyoda H, Kiriyama S, Tanikawa M, Hisanaga $Y$, et al. Viral eradication reduces all-cause mortality in patients with chronic hepatitis $\mathrm{C}$ virus infection: a propensity score analysis. Liver Int. 2016 (Epub 2016/01/21. Eng).

20. Kobayashi M, Hara T, Fukushima T, Kawamura Y, Sezaki H, Hosaka T, et al. Sustained viral response reduces liver complications and total mortality among Japanese elderly with hepatitis C virus infection. Hep Intl. 2014;8(1):S179.

21. Kutala BK, Guedj J, Asselah T, Boyer N, Mouri F, Martinot-Peignoux $\mathrm{M}$, et al. Impact of treatment against hepatitis $C$ virus on overall survival of naive patients with advanced liver disease. Antimicrob Agents Chemother. 2015;59(2):803-10.

22. Rutter K, Stättermayer AF, Beinhardt S, Scherzer TM, Steindl-Munda $P$, Trauner $M$, et al. Successful anti-viral treatment improves survival of patients with advanced liver disease due to chronic hepatitis C. Aliment Pharmacol Ther. 2015;41(6):521-31.

23. NIH. National Institutes of Health consensus development conference statement: management of hepatitis C: 2002-June 10-12, 2002. https:// consensus.nih.gov/2002/2002hepatitisc2002116 html.htm. Accessed 19 Dec 2015.

24. Nahon P, Bourcier V, Layese R, Petrov-Sanchez V, Guyader D, Dharancy S, et al. Benefits of HCV eradication in compensated cirrhotic patients extend beyond liver-related complications: results from the ANRS CO12 CIRVIR prospective cohort. Hepatology. 2015;62:1090A.

25. De Lisi S, Crosignani A, Roffi L, Rossi S, Boccaccio V, Zermiani $\mathrm{P}$, et al. SVR is associated with no risk reduction of HCC development in patients with HCV-related cirrhosis. A prospective, up-to 23 years, cohort follow-up study. Dig Liver Dis. 2014;46:e33-4.

26. Aleman S, Rahbin N, Weiland O, Davidsdottir L, Hedenstierna $M$, Rose $N$, et al. A risk for hepatocellular carcinoma persists long-term after sustained virologic response in patients with hepatitis C-associated liver cirrhosis. Clin Infect Dis. 2013;57(2):230-6.

27. McCombs JS, Tonnu-MiHara I, Matsuda T, McGinnis J, Fox S. Can hepatitis c treatment be safely delayed? Evidence from the veterans administration healthcare system. J Hepatol. 2015;62:S191.

28. Baser O, Altinbas A, Baser E, Kariburyo MF. Economic impact and complications of treated and untreated hepatitis $\mathrm{C}$ virus patients in Turkey. Value Health Reg Issues. 2015;7:42-8.

29. Coldea L. The frequency and the characteristics of extrahepatic manifestations associated with chronic hepatitis C. HPB. 2015;17:96-7.

30. Yilmaz Sİ, Erol S, Özbek A, Parlak M. Distribution of viral genotypes and extrahepatic manifestations in patients with chronic hepatitis $\mathrm{C}$ in Eastern Turkey. Turk J Med Sci. 2015;45(1):70-5.

31. Cheng ZJ, Zhou BT, Shi XC, Zhang Y, Zhang LF, Chen LM, et al. Extrahepatic manifestations of chronic hepatitis $C$ virus infection: 297 cases from a tertiary medical center in Beijing, China. Chin Med J. 2014;127(7):1206-10. 
32. Mazzaro C, Mauro E, Dal Maso L, Pozzato G. Prevalence of extrahepatic manifestations in infection with hepatitis C virus: study of 440 cases. Ital J Med. 2012;6(1):94.

33. Zarebska-Michaluk DA, Lebensztejn DM, Kryczka WM, Skiba E. Extrahepatic manifestations associated with chronic hepatitis $\mathrm{C}$ infections in Poland. Adv Med Sci. 2010;55(1):67-73.

34. Agnello V, Chung RT, Kaplan LM. A role for hepatitis $C$ virus infection in type II cryoglobulinemia. N Engl J Med. 1992;327(21):1490-5 (Epub 1992/11/19. eng).

35. Ferri C, Sebastiani M, Giuggioli D, Cazzato M, Longombardo G, Antonelli A, et al. Mixed cryoglobulinemia: demographic, clinical, and serologic features and survival in 231 patients. Semin Arthritis Rheum. 2004;33(6):355-74 (Epub 2004/06/11. eng).

36. Ramos-Casals M, Robles A, Brito-Zeron P, Nardi N, Nicolas JM, Forns $\mathrm{X}$, et al. Life-threatening cryoglobulinemia: clinical and immunological characterization of 29 cases. Semin Arthritis Rheum. 2006;36(3):189-96 (Epub 2006/09/26. eng).

37. Retamozo S, Diaz-Lagares C, Bosch X, Bove A, Brito-Zeron P, Gomez ME, et al. Life-threatening cryoglobulinemic patients with hepatitis c: clinical description and outcome of 279 patients. Medicine. 2013 (Epub 2013/08/27. Eng).

38. Saadoun D, Resche-Rigon M, Thibault V, Piette JC, Cacoub P. Antiviral therapy for hepatitis C virus-associated mixed cryoglobulinemia vasculitis: a long-term followup study. Arthritis Rheum. 2006;54(11):3696-706 (Epub 2006/11/01. eng).

39. Dal Maso L, Franceschi S. Hepatitis C virus and risk of lymphoma and other lymphoid neoplasms: a meta-analysis of epidemiologic studies. Cancer Epidemiol Biomark Prev. 2006;15(11):2078-85 (PMID: 17119031. Epub 2006/11/23. eng).

40. Matsuo K, Kusano A, Sugumar A, Nakamura S, Tajima K, Mueller NE. Effect of hepatitis C virus infection on the risk of non-Hodgkin's lymphoma: a meta-analysis of epidemiological studies. Cancer Sci. 2004;95(9):745-52 (Epub 2004/10/09. eng).

41. White DL, Ratziu V, El-Serag HB. Hepatitis C infection and risk of diabetes: a systematic review and meta-analysis. J Hepatol. 2008;49(5):831-44 (Epub 2008/09/26. eng).

42. Younossi ZM, Stepanova M, Nader F, Younossi Z, Elsheikh E. Associations of chronic hepatitis C with metabolic and cardiac outcomes. Aliment
Pharmacol Ther. 2013;37(6):647-52 (Epub 2013/02/07. eng).

43. Patel S, Jinjuvadia R, Patel R, Liangpunsakul S. Insulin resistance is associated with significant liver fibrosis in chronic hepatitis C patients: a systemic review and meta-analysis. J Clin Gastroenterol. 2016;50(1):80-4.

44. Kawaguchi T, Ide T, Taniguchi E, Hirano E, Itou M, Sumie S, et al. Clearance of HCV improves insulin resistance, beta-cell function, and hepatic expression of insulin receptor substrate 1 and 2 . Am J Gastroenterol. 2007;102(3):570-6 (Epub 2007/01/16. eng).

45. Dalrymple LS, Koepsell T, Sampson J, Louie T, Dominitz JA, Young B, et al. Hepatitis $C$ virus infection and the prevalence of renal insufficiency. Clin J Am Soc Nephrol. 2007;2(4):715-21 (Epub 2007/08/21. eng).

46. Lee JJ, Lin MY, Yang YH, Lu SN, Chen HC, Hwang SJ. Association of hepatitis $\mathrm{C}$ and $\mathrm{B}$ virus infection with CKD in an endemic area in Taiwan: a cross-sectional study. Am J Kidney Dis. 2010;56(1):23-31 (Epub 2010/04/20. eng).

47. He H, Kang R, Zhao Z. Hepatitis $C$ virus infection and risk of stroke: a systematic review and meta-analysis. PloS one. 2013;8(11):e81305 (Epub 2013/11/23. eng).

48. Liao CC, Su TC, Sung FC, Chou WH, Chen TL. Does hepatitis $\mathrm{C}$ virus infection increase risk for stroke? A population-based cohort study. PloS one. 2012;7(2):e31527 (Epub 2012/03/01. eng).

49. Butt AA, Xiaoqiang W, Budoff M, Leaf D, Kuller LH, Justice AC. Hepatitis $C$ virus infection and the risk of coronary disease. Clin Infect Dis. 2009;49(2):225-32 (Epub 2009/06/11. eng).

50. Younossi ZM, Henry L, Park H, Adeyemi A, Stepanova M. Depression and chronic hepatitis C (CH-C): a common and costly association. Am J Gastroenterol. 2015;110:S874-5.

51. Henry L, Whitley K, Dhakal K, Samuel L, Culler L, Bryns $\mathrm{M}$, et al. A systematic review assessing the impact of chronic hepatitis $\mathrm{C}$ on health-related quality of life and patient-reported outcomes. Am J Gastroenterol. 2014;109:S178.

52. Gragnani L, Fognani E, Piluso A, Boldrini B, Urraro $\mathrm{T}$, Fabbrizzi A, et al. Long-term effect of $\mathrm{HCV}$ eradication in patients with mixed cryoglobulinemia: a prospective, controlled, open-label, cohort study. Hepatology. 2015;61(4):1145-53 (Epub 2014/11/29. eng).

53. Kawamura Y, Ikeda K, Arase Y, Yatsuji H, Sezaki H, Hosaka T, et al. Viral elimination reduces incidence 
of malignant lymphoma in patients with hepatitis C. Am J Med. 2007;120(12):1034-41 (Epub 2007/12/07. eng).

54. Arase Y, Suzuki F, Suzuki Y, Akuta N, Kobayashi M, Kawamura Y, et al. Sustained virological response reduces incidence of onset of type 2 diabetes in chronic hepatitis C. Hepatology. 2009;49(3):739-44 (Epub 2009/01/08. eng).

55. Hassanein T, Cooksley G, Sulkowski M, Smith C, Marinos G, Lai MY, et al. The impact of peginterferon alfa-2a plus ribavirin combination therapy on health-related quality of life in chronic hepatitis C. J Hepatol. 2004;40(4):675-81 (Epub 2004/03/20. eng).

56. Chahal HS, Marseille EA, Tice JA, et al. Cost-effectiveness of early treatment of hepatitis $c$ virus genotype 1 by stage of liver fibrosis in a us treatment-naive population. JAMA Intern Med. 2016;176(1):65-73.

57. Ahmed A, Gordon SC, Saab S, Younossi Z. Evaluation of the health outcomes for ledipasvir/sofosbuvir in early vs. Delayed treatment according to fibrosis stage of patients with chronic hepatitis $\mathrm{C}$ virus (HCV) genotype 1 infection: results from a decision-analytic markov model. Hepatology. 2014;60:1041A.

58. Buti M, Domínguez-Hernández R, Oyagüez I, Rueda M, Casado MÁ. Early versus delayed use of sofosbuvir plus peginterferon/ribavirin therapy in fibrosis patients with hepatitis C virus: a cost-effectiveness analysis. J Hepatol. 2015;62:S666.

59. Misurski DA, Johnson SJ, Samp JC, Marx SE, Juday TR, Virabhak $S$, et al. Reduction in annual medical costs with early treatment of HCV using abbvie 3D (ABT-450/ritonavir/ombitasvir and dasabuvir) \pm ribavirin in the United States. J Hepatol. 2015;62:S642.

60. Razavi H, Waked I, Sarrazin C, Myers RP, Idilman R, Calinas $\mathrm{F}$, et al. The present and future disease burden of hepatitis $\mathrm{C}$ virus (HCV) infection with today's treatment paradigm. J Viral Hepat. 2014;21(Suppl 1):34-59 (Epub 2014/04/10. eng).

61. Semela D, Blach S, Bihl FK, Bruggmann P, Lavanchy $D$, Negro F, et al. The impact of time on a scenario to minimize complications of hepatitis $\mathrm{C}$ infection. Hepatology. 2014;60:912A.

62. Bruggmann P, Negro F, Bihl F, Hindman S, Lavanchy $\mathrm{D}$, Müllhaupt B, et al. The disease burden of chronic hepatitis $\mathrm{C}$ virus (HCV) infection in Switzerland. J Hepatol. 2014;60(1):S518.

63. Mitruka K, Tsertsvadze T, Butsashvili M, Gamkrelidze A, Sabelashvili P, Adamia E, et al.
Launch of a nationwide hepatitis C elimination program-Georgia, April 2015. MMWR Morb Mortal Wkly Rep. 2015;64(28):753-7.

64. Dashdorj NJ, Genden Z, Yagaanbuyant D, Dashdorj ND. Hepatitis prevention, control, and elimination program in Mongolia: innovation in combating viral hepatitis endemic. J Viral Hepat. 2015;22:130.

65. Muir AJ, Naggie S. Hepatitis C virus treatment: is it possible to cure all hepatitis $\mathrm{C}$ virus patients? Clin Gastroenterol Hepatol. 2015;13(12):2166-72.

66. ABC. Federal Government to spend $\$ 1$ billion on groundbreaking Hepatitis C treatments. http://www. abc.net.au/news/2015-12-20/federal-governmentspending-1billion-on-hepatitis-c-treatment/7043624. Accessed 19 Dec 2015.

67. IHS. French government proposes "universal" access to new HCV medicines. http://www.ihs.com/ country-industry-forecasting.html?ID=10659114512. Accessed 1 Mar 2016.

68. Labarga P, Barreiro P, De Mendoza C, Soriano V. Progression to advanced liver fibrosis in $\mathrm{HIV} / \mathrm{HCV}$ coinfected patients and prioritization of new hepatitis C therapies. J Hepatol. 2015;62:S651-2.

69. El-Serag HB, Hampel H, Yeh C, Rabeneck L. Extrahepatic manifestations of hepatitis $\mathrm{C}$ among United States male veterans. Hepatology. 2002;36(6):1439-45 (Epub 2002/11/26. eng).

70. Cacoub P, Poynard T, Ghillani P, Charlotte F, Olivi M, Piette JC, et al. Extrahepatic manifestations of chronic hepatitis C. MULTIVIRC Group. Multidepartment virus C. Arthritis Rheum. 1999;42(10):2204-12 (Epub 1999/10/19. eng).

71. Bonkovsky HL, Snow KK, Malet PF, Back-Madruga C, Fontana RJ, Sterling RK, et al. Health-related quality of life in patients with chronic hepatitis $\mathrm{C}$ and advanced fibrosis. J Hepatol. 2007;46(3):420-31 (Epub 2007/01/02. eng).

72. Romero-Gomez M, Fernandez-Rodriguez CM, Andrade RJ, Diago M, Alonso S, Planas R, et al. Effect of sustained virological response to treatment on the incidence of abnormal glucose values in chronic hepatitis C. J Hepatol. 2008;48(5):721-7 (Epub 2008/03/01. eng).

73. McHutchison JG, Ware JE Jr, Bayliss MS, Pianko S, Albrecht JK, Cort S, et al. The effects of interferon alpha-2b in combination with ribavirin on health related quality of life and work productivity. J Hepatol. 2001;34(1):140-7 (Epub 2001/02/24. eng).

74. Kang SC, Hwang SJ, Lee SH, Chang FY, Lee SD. Health-related quality of life and impact of antiviral 
treatment in Chinese patients with chronic hepatitis C in Taiwan. World J Gastroenterol. 2005;11(47):7494-8 (Epub 2006/01/27. eng).

75. Rasenack J, Zeuzem S, Feinman SV, Heathcote EJ, Manns M, Yoshida EM, et al. Peginterferon alpha-2a (40kD) [Pegasys] improves HR-QOL outcomes compared with unmodified interferon alpha-2a [Roferon-A]: in patients with chronic hepatitis C. PharmacoEconomics. 2003;21(5):341-9 (Epub 2003/03/12. eng).

76. Cacoub P, Ratziu V, Myers RP, Ghillani P, Piette JC, Moussalli $\mathrm{J}$, et al. Impact of treatment on extra hepatic manifestations in patients with chronic hepatitis C. J Hepatol. 2002;36(6):812-8 (Epub 2002/06/05. eng).

77. Aghemo A, Prati GM, Rumi MG, Soffredini R, D'Ambrosio R, Orsi E, et al. Sustained virological response prevents the development of insulin resistance in patients with chronic hepatitis C. Hepatology. 2012;56(5):1681-7 (Epub 2012/05/ 24. eng).

78. Gragnani L, Fabbrizzi A, Triboli E, Urraro T, Boldrini B, Fognani E, et al. Triple antiviral therapy in hepatitis $\mathrm{C}$ virus infection with or without mixed cryoglobulinaemia: a prospective, controlled pilot study. Dig Liver Dis. 2014;46(9):833-7 (Epub 2014/06/24. eng).

79. Kraus MR, Schafer A, Teuber G, Porst H, Sprinzl K, Wollschlager $S$, et al. Improvement of neurocognitive function in responders to an antiviral therapy for chronic hepatitis C. Hepatology. 2013;58(2):497-504 (Epub 2013/01/ 10. eng).

80. Thein HH, Krahn M, Kaldor JM, Dore GJ. Estimation of utilities for chronic hepatitis C from SF-36 scores. Am J Gastroenterol. 2005;100(3):643-51.

81. Taskoparan M, Serin E, Gokturk HS, Icer MO, Abaci $\mathrm{K}$, Ozer B, et al. Early effect of peginterferon alpha-2b plus ribavirin treatment on blood pressure and insulin resistance in patients with chronic hepatitis C. Hepato-gastroenterology. 2011;58(107-108):875-9 (Epub 2011/08/13. eng).

82. Byrnes V, Miller A, Lowry D, Hill E, Weinstein C, Alsop D, et al. Effects of anti-viral therapy and HCV clearance on cerebral metabolism and cognition. J Hepatol. 2012;56(3):549-56 (Epub 2011/10/27. eng).

83. Vallisa D, Bernuzzi P, Arcaini L, Sacchi S, Callea V, Marasca R, et al. Role of anti-hepatitis C virus (HCV) treatment in HCV-related, low-grade, B-cell, non-Hodgkin's lymphoma: a multicenter Italian experience. J Clin Oncol. 2005;23(3):468-73 (Epub 2005/01/22. eng).
84. Zhang S, Bastian ND, Griffin PM. Cost-effectiveness of sofosbuvir-based treatments for chronic hepatitis $\mathrm{C}$ in the US. BMC Gastroenterol. 2015;15:98 (Epub 2015/08/05. eng).

85. Younossi ZM, Park H, Saab S, Ahmed A, Dieterich D, Gordon SC. Cost-effectiveness of all-oral ledipasvir/sofosbuvir regimens in patients with chronic hepatitis $\mathrm{C}$ virus genotype 1 infection. Aliment Pharmacol Ther. 2015;41(6):544-63 (Epub 2015/01/27. eng).

86. Westerhout K, Treur M, Mehnert A, Pascoe K, Ladha I, Belsey J. A cost utility analysis of simeprevir used with peginterferon + ribavirin in the management of genotype 1 hepatitis $C$ virus infection, from the perspective of the UK National Health Service. J Med Econ. 2015;18(10):838-49 (Epub 2015/04/ 24. eng).

87. Warren E, Wright A, Jones B. Cost-effectiveness of telaprevir in patients with genotype 1 hepatitis $\mathrm{C}$ in Australia. Value Health. 2014;17(8):792-800 (Epub 2014/12/17. eng).

88. Vellopoulou A, van Agthoven M, van der Kolk A, de Knegt RJ, Berdeaux G, Cure S, et al. Cost utility of telaprevir-PR (peginterferon-ribavirin) versus boceprevir-PR and versus PR alone in chronic hepatitis $\mathrm{C}$ in The Netherlands. Appl Health Econ Health Policy. 2014;12(6):647-59 (Epub 2014/08/ 12. eng).

89. San Miguel R, Gimeno-Ballester V, Blazquez A, Mar J. Cost-effectiveness analysis of sofosbuvir-based regimens for chronic hepatitis C. Gut. 2015;64(8):1277-88 (Epub 2014/10/15. eng).

90. Saab S, Gordon SC, Park H, Sulkowski M, Ahmed A, Younossi Z. Cost-effectiveness analysis of sofosbuvir plus peginterferon/ribavirin in the treatment of chronic hepatitis $C$ virus genotype 1 infection. Aliment Pharmacol Ther. 2014;40(6):657-75 (Epub 2014/07/30. eng).

91. Rein DB, Wittenborn JS, Smith BD, Liffmann DK, Ward JW. The cost-effectiveness, health benefits, and financial costs of new antiviral treatments for hepatitis C virus. Clin Infect Dis. 2015;61(2):157-68 (Epub 2015/03/18. eng).

92. Pfeil AM, Reich O, Guerra IM, Cure S, Negro F, Mullhaupt $\mathrm{B}$, et al. Cost-effectiveness analysis of sofosbuvir compared to current standard treatment in Swiss patients with chronic hepatitis C. PloS One. 2015;10(5):e0126984 (Epub 2015/05/15. eng).

93. Petta S, Cabibbo G, Enea M, Macaluso FS, Plaia A, Bruno $\mathrm{R}$, et al. Cost-effectiveness of sofosbuvir-based triple therapy for untreated patients with genotype 1 chronic hepatitis C. 
Hepatology. 2014;59(5):1692-705 (Epub 2014/04/ 03. eng).

94. Petta S, Cabibbo G, Enea M, Macaluso FS, Plaia A, Bruno $\mathrm{R}$, et al. Personalized cost-effectiveness of boceprevir-based triple therapy for untreated patients with genotype 1 chronic hepatitis C. Dig Liver Dis. 2014;46(10):936-42 (Epub 2014/07/30. eng).

95. Najafzadeh M, Andersson K, Shrank WH, Krumme AA, Matlin OS, Brennan T, et al. Cost-effectiveness of novel regimens for the treatment of hepatitis $\mathrm{C}$ virus. Ann Intern Med. 2015;162(6):407-19 (Epub 2015/03/17. eng).

96. Liu S, Watcha D, Holodniy M, Goldhaber-Fiebert JD. Sofosbuvir-based treatment regimens for chronic, genotype 1 hepatitis $C$ virus infection in U.S. incarcerated populations: a cost-effectiveness analysis. Ann Intern Med. 2014;161(8):546-53 (Epub 2014/10/21. eng).

97. Liu S, Cipriano LE, Holodniy M, Owens DK, Goldhaber-Fiebert JD. New protease inhibitors for the treatment of chronic hepatitis C: a cost-effectiveness analysis. Ann Intern Med. 2012;156(4):279-90 (Epub 2012/02/22. eng).

98. Linas BP, Barter DM, Morgan JR, Pho MT, Leff JA, Schackman BR, et al. The cost-effectiveness of sofosbuvir-based regimens for treatment of hepatitis $\mathrm{C}$ virus genotype 2 or 3 infection. Ann Intern Med. 2015;162(9):619-29 (Epub 2015/03/ 31. eng).

99. Leleu H, Blachier M, Rosa I. Cost-effectiveness of sofosbuvir in the treatment of patients with hepatitis C. J Viral Hepat. 2015;22(4):376-83 (Epub 2014/09/16. eng).

100. Hagan LM, Yang Z, Ehteshami M, Schinazi RF. All-oral, interferon-free treatment for chronic hepatitis C: cost-effectiveness analyses. J Viral Hepat. 2013;20(12):847-57 (Epub 2013/12/07. eng).

101. Hagan LM, Sulkowski MS, Schinazi RF. Cost analysis of sofosbuvir/ribavirin versus sofosbuvir/simeprevir for genotype 1 hepatitis $\mathrm{C}$ virus in interferon-ineligible/intolerant individuals. Hepatology. 2014;60(1):37-45 (Epub 2014/03/29. eng).

102. Gimeno-Ballester V, Mar J, San Miguel R. Cost-effectiveness analysis of simeprevir with daclatasvir for non-cirrhotic genotype-1b-naive patients plus chronic hepatitis C. Expert Rev Pharmacoecon Outcomes Res. 2015:1-10 (Epub 2015/09/04. Eng).

103. Ferrante SA, Chhatwal J, Brass CA, El Khoury AC, Poordad F, Bronowicki JP, et al. Boceprevir for previously untreated patients with chronic hepatitis C Genotype 1 infection: a US-based cost-effectiveness modeling study. BMC Infect Dis. 2013;13:190 (Epub 2013/04/30. eng).

104. Elbasha EH, Chhatwal J, Ferrante SA, El Khoury AC, Laires PA. Cost-effectiveness analysis of boceprevir for the treatment of chronic hepatitis $\mathrm{C}$ virus genotype 1 infection in Portugal. Appl Health Econ Health Policy. 2013;11(1):65-78 (Epub 2013/01/29. eng).

105. Dan YY, Ferrante SA, Elbasha EH, Hsu TY. Cost-effectiveness of boceprevir co-administration versus pegylated interferon-alpha2b and ribavirin only for patients with hepatitis $C$ genotype 1 in Singapore. Antivir Ther. 2015;20(2):209-16 (Epub 2014/08/12. eng).

106. Cure S, Guerra I, Dusheiko G. Cost-effectiveness of sofosbuvir for the treatment of chronic hepatitis C-infected patients. J Viral Hepat. 2015;22(11):882-9 (Epub 2015/04/08. eng).

107. Cure S, Guerra I, Camma C, Craxi A, Carosi G. Cost-effectiveness of sofosbuvir plus ribavirin with or without pegylated interferon for the treatment of chronic hepatitis $\mathrm{C}$ in Italy. J Med Econ. 2015;18(9):678-90 (Epub 2015/04/22. eng).

108. Cure S, Bianic F, Gavart S, Curtis S, Lee S, Dusheiko G. Cost-effectiveness of telaprevir in combination with pegylated interferon alpha and ribavirin in treatment-experienced chronic hepatitis C genotype 1 patients. J Med Econ. 2014;17(1):77-87 (Epub 2013/09/17. eng).

109. Cure S, Bianic F, Gavart S, Curtis S, Lee S, Dusheiko G. Cost-effectiveness of telaprevir in combination with pegylated interferon alpha and ribavirin in previously untreated chronic hepatitis $C$ genotype 1 patients. J Med Econ. 2014;17(1):65-76 (Epub 2013/10/29. eng).

110. Chhatwal J, Kanwal F, Roberts MS, Dunn MA. Cost-effectiveness and budget impact of hepatitis $\mathrm{C}$ virus treatment with sofosbuvir and ledipasvir in the United States. Ann Intern Med. 2015;162(6):397-406 (Epub 2015/03/17. eng).

111. Chhatwal J, Ferrante SA, Brass C, El Khoury AC, Burroughs M, Bacon B, et al. Cost-effectiveness of boceprevir in patients previously treated for chronic hepatitis C genotype 1 infection in the United States. Value Health. 2013;16(6):973-86 (Epub 2013/09/18. eng).

112. Chan K, Lai MN, Groessl EJ, Hanchate AD, Wong JB, Clark JA, et al. Cost effectiveness of direct-acting antiviral therapy for treatment-naive patients with chronic HCV genotype 1 infection in the veterans 
health administration. Clin Gastroenterol Hepatol. 2013;11(11):1503-10 (Epub 2013/05/28. eng).

113. Camma C, Petta S, Enea M, Bruno R, Bronte F, Capursi V, et al. Cost-effectiveness of boceprevir or telaprevir for untreated patients with genotype 1 chronic hepatitis C. Hepatology. 2012;56(3):850-60 (Epub 2012/03/29. eng).

114. Camma C, Petta S, Cabibbo G, Ruggeri M, Enea M, Bruno R, et al. Cost-effectiveness of boceprevir or telaprevir for previously treated patients with genotype 1 chronic hepatitis C. J Hepatol. 2013;59(4):658-66 (Epub 2013/05/28. eng).

115. Brogan AJ, Talbird SE, Thompson JR, Miller JD, Rubin J, Deniz B. Cost-effectiveness of telaprevir combination therapy for chronic hepatitis C. PloS One. 2014;9(3):e90295 (Epub 2014/03/08. eng).

116. Blazquez-Perez A, San Miguel R, Mar J. Cost-effectiveness analysis of triple therapy with protease inhibitors in treatment-naive hepatitis $\mathrm{C}$ patients. PharmacoEconomics. 2013;31(10):919-31 (Epub 2013/09/04. eng).

117. Athanasakis K, Ferrante SA, Kyriopoulos, II, Petrakis I, Hill M, Retsa MP, et al. Boceprevir for chronic genotype 1 hepatitis $C$ virus in the current health care setting in Greece: a cost-effectiveness analysis. Clin Ther. 2015;37(7):1529-40 (Epub 2015/06/03. eng). 